\title{
Association Between Canine Malignant Lymphoma, Living in Industrial Areas, and Use of Chemicals by Dog Owners
}

\author{
Alessandra Gavazza, Silvano Presciuttini, Roberto Barale,
} George Lubas, and Biancaurora Gugliucci

\begin{abstract}
A case-control study was carried out to determine whether residential exposure to environmental pollutants increased risk for canine lymphoma in pet dogs. One hundred one cases with cytologically or histologically confirmed lymphoma diagnosed at a veterinary teaching hospital between the middle of 1996 and the middle of 1998 were examined. Controls were obtained by choosing twice the number of dogs without neoplastic disease, with overlapping distributions of province of residence, age, sex, and breed. Information regarding animal management, residence type, professional or hobby use of chemicals by owners, and treatment with herbicides or other pesticides in the area frequently visited by the dogs was obtained with a multiple-choice questionnaire by telephone interview. Two variables were positively and independently associated with the disease, namely residency in industrial areas (odds ratio $[\mathrm{OR}] ;=8.5 ; 95 \%$ confidence interval $[\mathrm{CI}], 2.3-30.9)$ and use of chemicals by owners, specifically paints or solvents $(\mathrm{OR}=4.6 ; 95 \% \mathrm{CI}, 1.7-12.6)$. A significantly lower value of the mean age of disease onset was found in the group of dogs at risk in comparison with the group of all other dogs $(6.1 \pm 0.4$ years, $\mathrm{n}=36$ versus $7.5 \pm 0.4$ years, $\mathrm{n}=65$, respectively; $P=.008)$. Variables describing animal care and pesticide use were either not associated with the disease or were uninformative. We suggest that canine lymphoma may be considered a sentinel of potentially hazardous situations for humans, because of the relatively short latency between exposure and disease onset.
\end{abstract}

Key words: Case-control study; Environmental pollution; Hemopoietic neoplasm.

$\mathbf{T}$ he occurrence of tumors in pet animals is a subject of increased interest, because they may represent sensitive indicators of environmental pollution. In particular, canine lymphoma shows histopathologic and biologic features similar to malignant non-Hodgkin's lymphoma (NHL) in humans. Indeed, canine lymphoma has often been proposed as an animal model of this kind of cancer. Lymphomas are relatively frequent in the dog (13-24 per 100,000 dogs), and represent about $83 \%$ of the entire hemopoietic neoplasms in this species. ${ }^{1-5}$ Because lymphoma is a spontaneously occurring tumor in a noninbred species that shares the environment of humans, canine lymphoma may be particularly suitable as a possible monitoring indicator of specific situations at increased risk for humans. A further advantage of adopting the $\operatorname{dog}$ as a sentinel species is the shorter latency between exposure and cancer onset in comparison with humans..$^{6-10}$

In human epidemiologic studies, NHL has been associated with exposure to chemicals such as phenoxyacetic acids, chlorophenols, dioxins, organic solvents including benzene, polychlorinated biphenyls, chlordanes, and immunosuppressive drugs. ${ }^{11-14}$ In dogs, an association has been reported between use of herbicides, in particular 2-4 dichlorochlorophenoxiacetic acid $(2,4-\mathrm{D}),{ }^{15}$ and NHL, although these results were followed by some criticism. ${ }^{15-17}$ A recent reevaluation of the same data failed to confirm a

From the Dipartimento di Clinica Veterinaria (Gavazza, Lubas, Gugliucci), and the Dipartimento di Scienze dell'Uomo $e$ dell'Ambiente (Presciuttini, Barale), University of Pisa, Pisa, Italy; and the Inherited Disease Research Branch, NHGRI, Baltimore, MD (Presciuttini).

Reprint requests: George Lubas, Associate Professor, Dipl ECVIM, Dipartimento di Clinica Veterinaria, Università di Pisa, v.le delle Piagge 2,Pisa,Italy; e-mail: labgsvet@vet.unipi.it.

Submitted January 3, 2000; Revised August 15, 2000; Accepted November 10,2000

Copyright (C) 2001 by the American College of Veterinary Internal Medicine

0891-6640/01/1503-0004/\$3.00/0 dose-response relationship. ${ }^{18}$ On the other hand, dogs exposed to herbicide-treated lawns had increased urinary excretion of 2,4-D. ${ }^{19}$ Another positive association has been documented with electromagnetic radiation exposure. ${ }^{20}$ The design of the present work was mainly aimed at studying the possible association of canine lymphoma with herbicide pollution through a case-control study in Italy.

\section{Materials and Methods \\ Cases and Controls}

Dogs with presumptive diagnosis of lymphoma are usually referred to our veterinary hospital coming from an area covering about two thirds of Tuscany. The present study was based on histopathologically or cytologically confirmed cases of malignant lymphoma, diagnosed consecutively between the middle of 1996 and the middle of 1998 . A total of 101 dogs were included (tumor staging: $15 \%$ III, 55\% IV, and $31 \% \mathrm{~V}$; anatomical types: $86 \%$ generalized, $9 \%$ alimentary, $3 \%$ thymic, $1 \%$ other forms). ${ }^{2}$

Controls were selected from a database of dogs with nonneoplastic diseases, referred to our hospital during the same period of time. For each case we used 2 randomly chosen dogs, with overlapping distributions with respect to province of residence, age, sex, and breed. When no control animals were available to match cases, we 1st released the requirement of same sex, then the requirement of the same province, and finally the requirement of the same breed. The requirement of same age group was never released.

\section{Questionnaire}

A standardized questionnaire was submitted to dog owners by telephone interview, always by the same person, 1 month to 1 year after NHL diagnosis (Table 1). The questionnaire was subdivided into 4 sections. (1) Animal care. Questions concerned the kind of diet (homemade, commercial, or both) and drinking water (tap, well, or both), whether or not external antiparasite treatment was used, the number of matings or pregnancies, and how long the dog had lived with the owner. (2) Type of home. Questions concerned type of neighborhood (categorized in 4 groups: rural area, town suburbs, town center, and industrial area) and type of premises (5 groups: no garden, garden, kitchen garden, open field, and combination of these). (3) Use of chemicals in or around the house. Questions concerned the presence 
jvim 15_309 Mp_191

File \# 09em

Table 1. Summary of the questionnaire and results of heterogeneity tests (Pearson chi-square) between cases and controls. See text for details.

\begin{tabular}{|c|c|c|c|c|c|}
\hline Variable Type & Variable & $\begin{array}{l}\text { Number of } \\
\text { Categories }\end{array}$ & $\begin{array}{c}\text { Number of } \\
\text { Answers } \\
\text { (Cases/Controls) }\end{array}$ & $\chi^{2}(d f)^{\mathrm{a}}$ & $P$ \\
\hline Matching variables & $\begin{array}{l}\text { Province of residence } \\
\text { Breed } \\
\text { Sex } \\
\text { Age }\end{array}$ & $\begin{array}{l}\text { Not fixed } \\
\text { Not fixed } \\
2 \\
\text { Not fixed }\end{array}$ & $\begin{array}{l}101 / 191 \\
101 / 191 \\
101 / 191 \\
101 / 191\end{array}$ & $\begin{array}{r}.89(4) \\
5.55(5) \\
.07(1) \\
(t \text {-test })\end{array}$ & $\begin{array}{l}.93 \\
.35 \\
.79 \\
.25\end{array}$ \\
\hline $\begin{array}{l}\text { Animal care } \\
\text { conduct }\end{array}$ & $\begin{array}{l}\text { Antiparasite treatments } \\
\text { Drinking water } \\
\text { Food } \\
\text { Number of matings } \\
\text { Number of pregnancies }\end{array}$ & $\begin{array}{l}\text { Y/N } \\
3 \\
3 \\
\text { Not fixed } \\
\text { Not fixed }\end{array}$ & $\begin{array}{c}90 / 190 \\
100 / 191 \\
101 / 191 \\
49 / 122 \\
33 / 59\end{array}$ & $\begin{array}{r}.62(1) \\
3.57(2) \\
3.60(2) \\
.05(2) \\
.29(2)\end{array}$ & $\begin{array}{l}.43 \\
.17 \\
.17 \\
.82 \\
.59\end{array}$ \\
\hline Type of residency & $\begin{array}{l}\text { Neighborhood type } \\
\text { Habitat type }\end{array}$ & $\begin{array}{l}4 \\
5\end{array}$ & $\begin{array}{l}100 / 190 \\
101 / 191\end{array}$ & $\begin{array}{r}15.2(3) \\
1.87(4)\end{array}$ & $\begin{array}{l}.002 \\
.76\end{array}$ \\
\hline $\begin{array}{l}\text { Owner activity and } \\
\text { profession }\end{array}$ & $\begin{array}{l}\text { Household with garage } \\
\text { Garage utilization } \\
\text { Use of chemicals } \\
\text { Profession }^{\mathrm{b}}\end{array}$ & $\begin{array}{l}\mathrm{Y} / \mathrm{N} \\
2 \\
\mathrm{Y} / \mathrm{N} \\
\text { Not fixed }\end{array}$ & $\begin{array}{r}101 / 190 \\
62 / 112 \\
100 / 190 \\
80 / 152\end{array}$ & $\begin{array}{r}.06(1) \\
5.50(1) \\
16.2(1) \\
11.1 \quad(1)\end{array}$ & $\begin{aligned} & .81 \\
& .019 \\
&<.0001 \\
& .001\end{aligned}$ \\
\hline Exposure to pesticides & $\begin{array}{l}\text { Pesticide use on premises } \\
\text { Pesticide type } \\
\text { Pesticide preparation } \\
\text { Pesticide use by neighbors } \\
\text { Regular visits to public garden } \\
\text { Pesticide use in public gardens } \\
\text { Open canals in visited areas }\end{array}$ & $\begin{array}{l}\mathrm{Y} / \mathrm{N} \\
7 \\
3 \\
\mathrm{Y} / \mathrm{N} \\
\mathrm{Y} / \mathrm{N} \\
\mathrm{Y} / \mathrm{N} \\
\mathrm{Y} / \mathrm{N}\end{array}$ & $\begin{array}{l}99 / 167 \\
42 / 70 \\
12 / 67 \\
33 / 110 \\
53 / 105 \\
22 / 51 \\
100 / 188\end{array}$ & $\begin{array}{l}0.00(1) \\
\mathrm{NI} \\
\mathrm{NI} \\
1.03(1) \\
.36(1) \\
.70(1) \\
1.71(1)\end{array}$ & $\begin{array}{l}.31 \\
.55 \\
.40 \\
.19\end{array}$ \\
\hline
\end{tabular}

Y, yes; N, no; NI, not informative (see text).

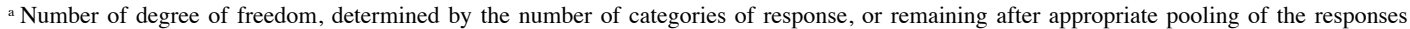
with no predetermined number of categories.

${ }^{\mathrm{b}}$ Computed variable.

of a garage in the household, the use of the garage as a storeroom (ie, not only for car parking), the profession of the owner, and the manipulation of potentially toxic substances in the area usually visited by the dog (the following itemized list was submitted: 1, paints; 2, solvents; 3 , adhesives; 4, gasoline; 5 , diesel fuel; 6, lubricants; 7, others, with specification). (4) Use of herbicides and other pesticides in the house premises or around it. Questions included pesticide use in the garden (yes/no $[\mathrm{Y} / \mathrm{N}])$, type of pesticide used (8 possible choices), method of pesticide preparation, use of pesticides by neighbors $(\mathrm{Y} / \mathrm{N})$, regular visits of public gardens by the $\operatorname{dog}(\mathrm{Y} / \mathrm{N})$, pesticide use in public gardens $(\mathrm{Y} / \mathrm{N})$, and presence of open canals in the areas usually visited by the $\operatorname{dog}(\mathrm{Y} / \mathrm{N})$.

\section{Data Analysis}

Contingency tables were obtained for all variables of interest. Expectations and Pearson chi-square values of heterogeneity were computed in Excel. ${ }^{\text {a }}$ We did not examine contingency tables with more than 1 degree of freedom if more than one fifth of the cells had expected values lower than 5 or any cell an expected value of less than 1 . When such a case occurred, we pooled the data of similar categories. Crude odds ratios (ORs) with $95 \%$ confidence intervals (CIs) were computed as a measure of association among data reduced to 2

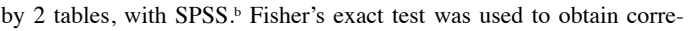
sponding probability levels. Differences between the means of the age of disease onset among selected groups of animals were assessed by 2 -tailed $t$-tests. Values were expressed as mean \pm standard error. No pairing of case-controls was used.

\section{Results}

Data were evaluated in 101 cases and 191 controls. In a few cases, the owners of control animals refused to participate. No new control animals were selected in these circumstances. All cases had at least 1 fully matching control animal. We 1st performed explorative analysis, comparing cases and controls for the frequency distribution of the matching variables. (I) Age. The requirement of the same age group $(0-3,4-6,7-9,10-12,13+$ years $)$ between cases and controls was satisfied for all animals. Mean ages were $7.0 \pm 0.3$ years among cases and $6.6 \pm 0.2$ years among controls ( $P$ not significant, $t$-test). (II) Breed. About $60 \%$ of the dogs belonged to the 5 most-represented breed groups, namely mixed breed (23\%), German Shepherd Dog (15\%), Setter (English, Irish, and Gordon, 10\%), Boxer (7\%), and Doberman Pinscher (5\%). An increased susceptibility to lymphoma has been reported for some breeds, in particular for Boxers. ${ }^{5}$ In fact, Boxers were slightly overrepresented among cases, contributing the highest value to the total $\chi^{2}$ (1.68); this bias may be attributed to a certain difficulty we had to find enough control animals of this breed. Although we were forced to release the requirement of the same breed between cases and controls in some instances, the overall breed distribution showed no indication of heterogeneity $\left(\chi^{2}=5.55,5 d f, P=.35\right)$. Because no canine census data are available in Tuscany, we did not 
Table 2. Distribution of cases and controls by type of neighborhood and chi-square values of heterogeneity.

\begin{tabular}{lcccc}
\hline Territory Type & Cases & Controls & Total & $\chi^{2}$ \\
\hline Rural zone & 46 & 88 & 134 & 0.00 \\
Periphery & 16 & 35 & 51 & 0.22 \\
Town center & 26 & 64 & 90 & 1.25 \\
Industrial area & 12 & 3 & 15 & 13.8 \\
Total & 100 & 190 & 290 & 15.2 \\
Probability & & & & 0.0016 \\
\hline
\end{tabular}

stratify cases by breed in the present work. (III) Province. About $75 \%$ of the dogs were from the provinces of Pisa and those (neighboring) of Florence, Lucca, and Leghorn. The others were from other provinces of Tuscany, with a few exceptions coming from outside Tuscany. The number of dogs per province was aggregated in 5 categories. As expected, the distribution showed a similarity between cases and controls a little higher than expected by chance $\left(\chi^{2}\right.$ $=0.89,4 d f, P=.93)$. Sex ratios were 64 males to 37 females (cases) and 124 males to 67 females (controls) $\left(\chi^{2}\right.$ $=0.07,1 d f, P=.79)$.

\section{Animal Care}

All owners interviewed said the dog had lived with them for its entire life. None of the variables of the group of questions relevant to animal care, which included diet type, source of drinking water, use of external antiparasite, and number of matings or pregnancies, were significantly different between cases and controls (the latter 2 variables were grouped in 2 classes, 0 and $\geq 1$ ). It may be worth noting that $11 \%$ of all owners used commercial food only, $7 \%$ administered well water only, and $12 \%$ did not treat dogs for parasites.

\section{Type of Home}

Two questions were aimed at identifying the type of neighborhood and the type of premises. Although the latter variable did not show any evidence of diversity between cases and controls $\left(\chi^{2}=1.87,4 d f, P=.76\right)$, the type of neighborhood differed significantly (total $\chi^{2}=15.2,3 d f$, $P=.0016$ ). The category "industrial area" is responsible for practically all the deviation observed, with 12 cases (expected 5.2) versus 3 controls (expected 9.8) (Table 2). This result justified contrasting the number of dogs living in industrial areas against all others in a 2 by 2 table. The resulting OR was 8.5 (95\% CI, 2.3-30.9).

\section{Owner Activity and Profession}

Four questions concerned use or storage of chemicals by the owners in the dogs' environment, either for hobby or professional use. A dramatic difference between cases and controls was immediately apparent with respect to the number of owners choosing 1 or more of the proposed substances. Thirty-five owners of cases (35\%) answered positively, against 29 of $190(15 \%)$ of controls (OR $=3.0 ; 95 \% \mathrm{CI}$, 1.7-5.4; $P<.0001)$. The expressed choice often implied multiple items. However, they could easily be aggregated
Table 3. Chemicals used or stored by dog owners in household areas inhabited by dogs. The three categories A, $\mathrm{B}$, and $\mathrm{C}$ are mutually exclusive.

\begin{tabular}{|c|c|c|c|c|c|}
\hline Group & Cases & $\begin{array}{l}\text { Con- } \\
\text { trols }\end{array}$ & Total & OR & $95 \% \mathrm{CI}$ \\
\hline (A) Paints and solvents & 13 & 11 & 24 & 3.0 & $1.3-7.0$ \\
\hline (B) Fuels and oils & 9 & 12 & 21 & 1.9 & $0.8-4.7$ \\
\hline (C) Both A and B & 13 & 6 & 19 & 5.5 & $2.0-15.0$ \\
\hline Subtotal $(A+B+C)$ & 35 & 29 & 64 & 3.0 & $1.7-5.4$ \\
\hline No use of chemicals & 64 & 161 & 225 & & \\
\hline Grand total & 99 & 190 & 289 & & \\
\hline
\end{tabular}

OR, odds ratio; $\mathrm{CI}$, confidence interval.

into 3 mutually exclusive categories: (A) paints and solvents, (B) fuels and lubricants, and (C) both A and B (Table 3). A total of 24 owners used only group A chemicals, 21 owners used only group B chemicals, and 19 owners used both $\mathrm{A}$ and $\mathrm{B}$. Both groups $\mathrm{A}$ and $\mathrm{C}$ showed ORs higher than 1.0 at the $95 \%$ level (3.0 and 5.5, respectively), whereas for group B the OR was not significantly different from 1.0. This suggests that an important risk factor for canine lymphoma is associated with owners' use of paints and solvents rather than of petroleum derivatives (fuels and lubricants).

An independent support of the above result derived from an analysis of garage utilization. Two questions regarded the presence of a garage in the house and its use by the owner as an automobile parking space only or as a workshop and/or storage room. Although the proportion of houses with a garage was remarkably similar between cases and controls (59\% versus $60 \%$, respectively), garage usage was significantly different. Forty-five out of 62 (73\%) case owners employed the garage for "other uses," often involving the utilization of group A and B compounds, in comparison with 61 of $112(54 \%)$ of control owners (OR $=2.2 ; 95 \%$ CI $1.1-4.3 ; P=.019)$. Further evidence of a possible association between chemical usage and canine lymphoma derived from a survey of owners' profession. Professions of all owners were labeled $(\mathrm{Y} / \mathrm{N})$ with respect to their potential utilization of chemicals (eg, artisans of leather, wood, or marble; owners of shoe or furniture factories managed by their families; painters; and auto-transporters were considered at higher risk; employees, professionals, and shop keepers, were considered at lower risk; and retired persons were marked as unknown). A total of 232 owners was classified by these criteria. The proportion of professions at risk was higher among cases than among controls (cases: 14/80, 18\%; controls 20/152, 13\%), but the difference did not reach statistical significance. However, when we stratified the 34 individuals labeled " $Y$ " by case and control and their actual use of chemicals, 9 of 11 cases declared they made use of group-A or group-B substances, against 5 of 23 among controls (OR $=16.2$; 95\% CI, 2.6$100.4 ; P<.001)$. The same analysis performed in the remaining 198 individuals considered to be at lower risk produced an OR of 2.1 (95\% CI, 1.0-4.1). This result supports the idea that a certain proportion of canine lymphomas may be attributable to intoxication associated with owners' profession, rather than to the use of chemicals for hobby. 


\section{Exposure to Pesticides}

Seven questions were aimed at finding a possible effect of pesticide application in owners' homes or nearby. A Y/ $\mathrm{N}$ question asked if any kind of pesticide was used in the garden, and no significant difference was observed (41/99 cases and 69/167 controls answered positively). On the other hand, the answers on the type of pesticide being applied and the mode of preparation were poorly informative. The finding emerged that people were generally unable to subclassify treatments by category (ie, herbicides, fungicides, insecticides, and so on; only the distinction between rodenticides and all other treatments was clear to everyone). Pesticide use by neighbors was not significant $(21 / 33$ cases versus 59/110 controls answered positively). About one half of both cases and controls declared that their dog regularly visited public gardens, but very few of the owners were able to answer the question about pesticide use in these areas. The questions about the presence of open canals around dogs' homes (a possible source of contamination by pesticides for dogs) did not show any difference between cases and controls.

Because it is reasonable to expect that contamination from pesticides is correlated with living in agricultural environments, we considered specifically the subgroup of cases and controls coming from rural areas (cases: $n=46$; controls: $\mathrm{n}=88$ ). They represented about one half of our entire database. The 2 most critical questions were use of pesticides by dog owners, and use of pesticides by neighbors. Neither of the 2 variables showed evidence of association (27/44 cases and 47/84 controls answered positively to question 1,13/17 cases and 45/62 controls answered positively to question 2). The other questions about pesticide treatment, as already noted, were poorly informative.

\section{Age Distribution among Cases}

A prediction based on the result that owners' use of chemicals increases risk for pet dogs is that some difference should be observed between subgroups of cases for variables related to disease risk, when cases are stratified by the putative risk factor. We considered the age at diagnosis among cases, and categorized them by the 2 main risk factors identified in the present work (residency in industrial areas and owners making use of toxic substances). A significantly lower value characterized the group with owners making use of toxic substances. Mean value $( \pm \mathrm{SE}$ of the mean) in this group was $6.1 \pm 0.4$ years $(\mathrm{n}=36)$, compared to $7.5 \pm 0.4$ years $(\mathrm{n}=65)$ in the opposite group $(P=.008,2$-tailed $t$-test). Similarly, dogs living in industrial areas had a mean age of $5.6 \pm 0.9$ years $(\mathrm{n}=12)$, compared to $7.2 \pm 0.3$ years in all other cases $(n=89)$. However, the $t$-test was not significant in this case, possibly because of the small sample size $(P=.091)$.

We tested for a possible correlation between living in an industrial area and the use of chemicals by owners. The 2 conditions showed a positive association $(\mathrm{OR}=2.0 ; 95 \%$ CI, 0.6-7.0), albeit not statistically significant (6 cases had both risk factors, against a chance expectation of $4.2 ; P=$ .25). Therefore, we pooled the cases with either or both of the risk factors in a single subgroup, and compared them with the cases with none of the 2 . Figure 1 shows the dis-

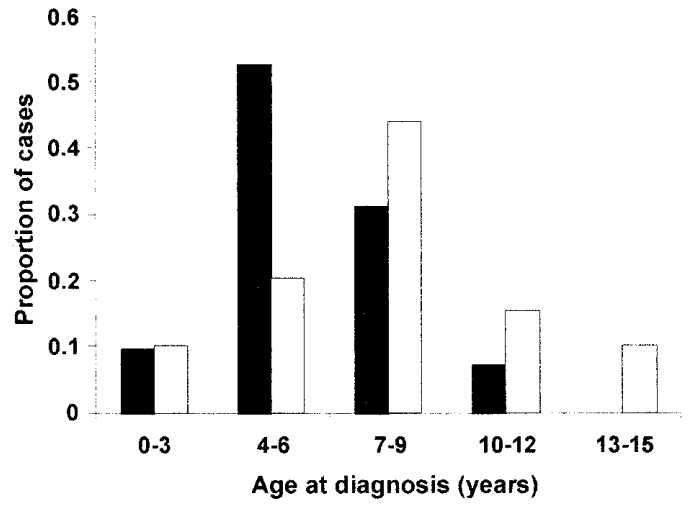

Fig 1. Distribution of the age at diagnosis from non-Hodgkin's lymphoma, of dogs with either or both of the identified risk factors (filled columns, $n=42$ ) and those with neither of the 2 risk factors (open columns, $\mathrm{n}=59$ ).

tribution of the age at diagnosis in these 2 subgroups of cases. The earlier age of lymphoma onset in the dogs at higher risk is apparent. Means were $6.1 \pm 0.4$ years $(\mathrm{n}=$ $42)$, and $7.7 \pm 0.4$ years $(n=59)$ in the high-risk and lowrisk groups, respectively ( $P=.004,2$-tailed $t$-test).

\section{Discussion}

Interest is increasing in pet dog epidemiologic studies aimed at detecting possible cancer risk factors for humans. Studies have shown that both humans and dogs can develop similar tumors as a consequence of exposure to similar substances, such as in the cases of passive smoking and asbestos. ${ }^{7,10,22,23}$ In particular, case-control studies have documented increased risk of lymphoma in dogs exposed to herbicides and to electromagnetic fields, which are also often regarded as possible risk factors for cancer in humans.

The design of the present study was mainly aimed at confirming and substantiating the previously reported association between dog NHL and herbicide pollution in dogs' micro- or macrohabitats. For this reason, we paid special attention to design the questionnaire in such a way as to obtain useful information about herbicides and other pesticides. An unexpected problem from this point of view was that interviewed owners were considerably unaware of the type of treatment applied to their gardens or fields or to areas nearby. They generally asked experts about the commercial product to apply at any given time during the season, and did not care about the type of pest being fought. Therefore, the only possible effect that we could detect in the present study was a general effect of exposure to pesticides (all treatments included) on NHL in our dog population. We found no evidence of association. The simplest hypothesis to explain this lack of effects is that no difference occurred between cases and controls with respect to exposure, ${ }^{18}$ or that the category of "pesticide" was too broad. This conjecture come from the geography of Tuscany, where finding wide agricultural areas treated with the same pesticide is virtually impossible. Rather, the region is densely inhabited, and the territory is fractioned into small 
holdings, often neighboring on small industrial or residential settlements. In such a patchy environment, determining whether a single dog has been exposed to pesticides may be intrinsically difficult; risk factors other than pesticide exposure may be more discriminating.

These considerations underline the importance of cultural differences between different societies in determining different patterns of association between environmental factors and disease, particularly in pet animals. Geographic movement of humans is scarce in Tuscany. People tend to remain in the same village or town for their entire life, often participating to the small company belonging to their family for generations. This often means that homes coincide, or are in close proximity, with working places. Therefore, pet dogs tend to stay in the same environment lifelong, and to be constantly exposed to whatever pollutant is spread in their microhabitat.

Unexpectedly, we found 2 variables significantly and independently associated with NHL: living in industrial areas, and use of chemicals by owners, specifically paints and solvents. The ORs were 8.5 and 5.5 , respectively. These values are larger than those reported for exposure to herbicides (OR up to 2.0) and may have masked their effect. ${ }^{15}$

An increased risk of NHL in humans living in urban areas with high concentration of industrial activity involving the frequent exposure to organic solvents recently has been documented.$^{24}$ Interestingly, in our dog cases, the excess of risk was found to be associated with exposure to paints and solvents, and apparently not with exposure to petroleum fuels and oils. It is worth noting that the exposure to the latter compounds also has been reported not to be associated with human NHL risk. ${ }^{25} \mathrm{~A}$ similar correlation was reported earlier in relation to another canine cancer. ${ }^{26}$ That study reported a significant positive correlation between the mortality from bladder cancer in dogs and the overall level of industrial activity of their county of residence, together with a similar correlation in humans. Thus, our study provides further support to the idea that pet animals may help provide insight into the role of environmental factors in the development of human cancer and may serve as valuable sentinel models to identify environmental health hazards for humans.

The finding that the age of onset of NHL in the cases potentially exposed to chemicals by owners' activity decreased by 1.4 years compared to nonexposed cases (from 7.5 to 6.1 years) reinforces the notion of a causal relationship between exposure and this type of cancer. In fact, a carcinogenic agent is considered as such if it is able to increase the probability of developing cancer during the whole lifespan or to anticipate its onset. Moreover, if we consider living in industrial areas as an additional risk factor, the anticipation of NHL in exposed cases increases up to 1.6 years.

A potential weakness of the present study should be pointed out. A critically important source of bias in studying the prevalence of cancer in animals is the influence of owners' commitment and attitude to pursue diagnostics and treatment for their pets. A strongly different inclination to refer animals with lymphomas compared to animals with nonneoplastic diseases by owners belonging to different demographic strata could have caused the association ob- served in the present study. For example, if a difference between urban and rural dogs was that the first are viewed as family members rather than farm dogs, then the observed overrepresentation of dogs with lymphomas from industrial and urban areas could reflect a higher disposition of urban owners to ask for medical care in the presence of this disease. Although the effect we observed was specific of residents in industrial areas, that is, excluding other urban environments (town center or suburbs), these potential sources of bias should be taken into account in studies aimed at confirming the present results. A section of the questionnaire should be devoted to evaluating owners' lifestyles that could influence their attitude and preference to pursue diagnostics and treatment for their dogs. These may include household income, level of education, and, in particular, the relationship between the dog and the owners and their families.

Other potential weaknesses of the present work are inherent to the case-control study design. A source of error that is difficult to control is the recall bias. If, for example, owners of case animals were more likely to remember or report using toxic substances, a false association of this feature with lymphoma would emerge. We found several independent results arguing against such a bias in the present study. The answer about the use of the garage as a storeroom is hardly conceivable as being influenced to recall bias, and the analysis of owners' professions is independent of any recall. However, in general, such types of biases should be addressed in future studies, for example, by designing analyses based on biological markers of exposure, such as DNA adducts. ${ }^{27}$

The present study suggests several lines of further investigation. The problem of the effects of specific herbicides probably must be addressed by means other than a questionnaire administered to dog owners, at least in our region. The issue of owners' professions and use of chemicals could be addressed in more detail by a specifically designed questionnaire, attempting to estimate the level and duration of dog exposure, possibly involving animals that are geographic neighbors of cases. In addition, the result of the association between NHL in dogs and living in an industrial area in the present study was based on a subjective assessment made by owners, and could be rendered more objective in a study specifically designed to investigate this effect. Finally, another possible strategy to define a sentinel animal model would be to select for analysis only dogs belonging to breeds known for being at higher risk of particular cancers, lymphoma in the present study. The effects of exposure to environmental pollutants may be increased in these animals. This would circumvent the difficulty in doing epidemiologic studies in animals when no active canine tumor registries exist.

\section{Footnotes}

a Microsoft Excel 2000, Seattle, WA

${ }^{\mathrm{b}}$ SPSS 7.0, Chicago, IL 
jvim 15_309 Mp_195

File \# 09em

\section{References}

1. Jain NC. The leukemias. In: Jain NC, ed. Essential of Veterinary Hematology. Philadelphia, PA: Lea \& Febiger; 1993:319-346.

2. Couto CG, Hammer AS. Diseases of the lymph nodes and the spleen. In: Ettinger SJ, Feldman EC, eds. Textbook of Veterinary Internal Medicine, Vol 2, 4th ed. Philadelphia, PA: WB Saunders Company; 1995:1937-1938.

3. Foon KA, Fisher RI. Lymphomas. In: Beutler E, Lichtman MA Coller BS, Kipps TJ, eds. Williams Hematology, 5th ed. New York, NY: McGraw Hill; 1995:1076-1096.

4. Capurro C, Buracco P, Rossi L. Il linfoma nel cane: Aspetti clinici ed opzioni terapeutiche. Veterinaria 1990;4:15-29.

5. Teske E. Canine malignant lymphoma: A review and comparison with human non-Hodgkin's lymphoma. Vet Q 1994;16:209-219.

6. Nordstoga K, Arnesen K, Gamlen H, et al. Cancer in dogs in Norway. Eur J Comp Anim Pract 1997;7:41-47.

7. Glickman LT, Domanski LM, Maguire TG, et al. Mesothelioma in pet dogs associated with exposure of their owners to asbestos. Environ Res 1983;32:305-313.

8. Reif JS, Bruns C, Lower KS. Cancer of the nasal cavity and paranasal sinuses and exposure to environmental tobacco smoke in pet dogs. Am J Epidemiol 1998;147:488-492.

9. MacEwen EG. Spontaneous tumors in dogs and cats: Models for the study of cancer biology and treatment. Cancer Metastasis Rev 1990;9:125-136.

10. Reif JS, Dunn K, Ogilvie GK, et al. Passive smoking and canine lung cancer risk. Am J Epidemiol 1992;135:234-239.

11. Hardell L, Eriksson M, Lennet P, et al. Malignant lymphoma and exposure to chemicals especially organic solvents, chlorophenols and phenoxy acids, a case-control study. Br J Cancer 1981;43:169171.

12. Hardell L, Lindstrom G, Bavel B, et al. Some aspects of the etiology of non-Hodgkin's lymphoma. Environ Health Perspect 1998; 106(Suppl 2):679-681.

13. Zahm SH, Blair A. Pesticides and non-Hodgkin lymphoma. Cancer Res 1992;52(Suppl):5485s-5488s.

14. Hayes RB, Yinn SN, Dosomeci M, et al. Benzene and the doserelated incidence of hematologic neoplasms in China. Chinese Academy of Preventive Medicine-National Cancer Institute Benzene Study Group. J Natl Cancer Inst 1997;89:1065-1071.
15. Hayes HM, Tarone RE, Cantor KP, et al. Case-control study of canine malignant lymphoma: Positive association with dog owner's use of 2,4-dichlorophenoxyacetic acid herbicides. J Natl Cancer Inst 1991;83:1226-1231

16. Carlo GL, Cole P, Miller AM, et al. Review of a study reporting an association between 2,4-dichlorophenoxyacetic acid and canine malignant lymphoma: Report of an expert panel. Reg Toxicol Pharmacol 1992;10:245-252.

17. Hayes HM, Tarone RE, Cantor KP. On the association between canine malignant lymphoma and opportunity for exposure to 2,4-dichlorophenoxyacetic acid. Environ Res 1995;70:119-125.

18. Kaneene JB, Miller R. Re-analysis of 2,4-D use and the occurrence of canine malignant lymphoma. Vet Hum Toxicol 1999;41(3): 164-170.

19. Reynolds PM, Reif JS, Ramsdell HS. Canine exposure to herbicide-treated lawns and urinary excretion of 2,4-dichlorophenoxyacetic. Cancer Epidemiol Biomarkers Prev 1994;3:233-237.

20. Reif JS, Lower KS, Ogilvie GK. Residential exposure to magnetic fields and risk of canine lymphoma. Am J Epidemiol 1995;141: 352-359.

21. Gavazza A, Presciuttini S, Barale R, et al. Risultati preliminari su fattori di rischio ambientale nel linfoma non-Hodgkin's del cane. Atti Soc Ital Sci Vet 1998;LII:279-280.

22. Trichopulos D, Kalandidi A, Sparros L, et al. Lung cancer and passive smoking. Int J Cancer 1981;27:1-4.

23. Dodoli D, Del Nevo M, Fiumalbi C, et al. Environmental household exposures to asbestos and occurrence of pleural mesothelioma. Am J Ind Med 1992;21:681-687.

24. Masala G, Di Lollo S, Picoco C, et al. Incidence rates of leukemias, lymphomas and myelomas in Italy: Geographic distribution and NHL hystotypes. Int J Cancer 1996;68:156-159.

25. IARC Working Group on the Evaluation of Carcinogenic Risks to Humans. Some Organic Solvents, Resin Monomers and Related Compounds, Pigments and Occupational Exposures in Paint Manufacture and Painting, Vol 47. Lyon, France; 1988:1-535.

26. Hayes HM, Hoover R, Tarone RE. Bladder cancer in pet dogs: A sentinel for environmental cancer? Am J Epidemiol 1981;114:229 233

27. O'Connor SR, Farmer PB, Lauder I. Benzene and non-Hodgkin's lymphoma. J Pathol 1999;189(4):448-453. 